\title{
Treating Severe Hyperkalemia with Renal Replacement Therapy in Acute Kidney Failure Due To Rhabdomyolysis
}

\author{
Alfred Ibrahimi ${ }^{\star}$, Saimir Kuci, Ervin Bejko, Stavri Llazo, Esmerilda Bulku, Diana Dhimitri, Ilir Ohri
}

Department of Anesthesiology and Intensive Care, Tirana University Hospital "Mother Thereza", Tirana, Albania

\author{
Citation: Ibrahimi A, Kuci S, Bejko E, Llazo S, \\ Bulku E, Dhimitri D, Ohri I. Treating Severe \\ Hyperkalemia with Renal Replacement Therapy \\ in Acute Kidney Failure Due To \\ Rhabdomyolysis. OA Maced J Med Sci. 2014
Jun $2(2): 313-315$ \\ http://dx.doi.org/10.3889/oamjms.2014.053 \\ Key words: Hyperkalemia; Myoglobinuria; \\ Rhabdomyolisis; Acute renal failure; CRRT. \\ "Correspondence: Mr. Alfred Edir Ibrahimi. \\ Mother Theresa Hospital - Anesthesilogy, Tiran \\ 004, Albania. Phone: 00355672073581 . E-Mail: \\ alfredibrahimi@hotmail.com \\ Received: 05-Mar-2014; Revised: 20-Apr- \\ 2014; Accepted: 23-Apr-2014; Online first: \\ 19-May-2014 \\ Copyright: () 2014 Ibrahimi et al. This is an \\ open access article distributed under the terms \\ of the Creative Commons Attribution License, \\ which permits unrestricted use, distribution, \\ and reproduction in any medium, provided the \\ original author and source are credited. \\ Competing Interests: The authors have \\ declared that no competing interests exist.
}

\section{Abstract}

Rhabdomyolysis and myoglobinuria are the main cause of the acute renal failure. Hyperkalemia is life threating complication of rhabdomyolisis due to massive cell destruction. We report a case of very severe hyperkalemia treated successfully with high volume hemodiafiltration (CVVHDF).

\section{Introduction}

Rhabdomyolysis is a syndrome caused by skeletal muscle cells destruction which can occur for many reasons, including prolonged ischemia, immobilization, and trauma. The main complication of the syndrome is the development of acute renal failure. Rhabdomyolysis and myoglobinuria are responsible for approximately $5 \%$ of all causes of acute renal failure [1]. The cause of rhabdomyolysis is often multifactorial, and approximately $8-20 \%$ of such patients develop myoglobinuric acute renal failure [2].

Rhabdomyolysis is a process characterized from the destruction of the muscle cells, which leads to increased circulatory levels of the intracellular content like electrolytes, sarcoplasmatic myoglobine, and proteins. Acute renal failure is the main complication of the severe rhabdomyolysis. The prognosis of the acute renal failure is worse when the cause of the Rhabdomyolysis is trauma. We have to take in consideration the fact that the conventional dialysis does not eliminate the myoglobine, so the use of hemodiafiltration with super high- flux dialysis membrane could be an alternative of the treatment in these patients.

Our aim is to present a case of acute renal failure with hyperkalemia, due to rhabdomyolisis, treated with high volumes of hemodiafiltration.

\section{Case Presentation}

A 76-year-old woman presents to our hospital transferred from a regional hospital with the diagnosis of acute lower limb ischemia (bilateral) for more than 24 hours. The patient complains of pain in the legs, during rest, more prominent at the right. In the objective examination is noted the absence of femoral pulse to the right and in the popliteal artery to the left. Her medical history includes chronic atrial fibrillation, treated with beta blocker and aspirin, hypertension, dyslipidemia, non-insulin-dependent diabetes, and 
mild chronic renal insufficiency (baseline creatinine $1.4 \mathrm{mg} / \mathrm{dL})$.

Blood sample analysis at admission was the following: creatinine $1.74 \mathrm{mg} / \mathrm{dL}$, urea $80 \mathrm{mg} / \mathrm{dL}$ with oligo anuria, and the patient was transferred to operating room (OR).

The surgery consists in removing the old and new thrombus via catheters Fogarty on both femoral arteries. After the intervention the patient was admitted to the ICU

At the time of admission to the ICU, blood sample analysis showed the following: creatinine $1.76 \mathrm{mg} / \mathrm{dL}$, urea $80 \mathrm{mg} / \mathrm{dL}$, and potassium $5.4 \mathrm{mEq} / \mathrm{L}$, and arterial blood gas analysis showed metabolic acidosis: $\mathrm{pH} 7.29,-7.6$ base excess, serum bicarbonate $16 \mathrm{mEq} / \mathrm{L}$, partial pressure of oxygen $79 \mathrm{mmHg}$ and partial pressure of carbon dioxide 28.9 $\mathrm{mmHg}$ of creatine phosphokinase (CK) $8500 \mathrm{U} / \mathrm{L}$, with oliguria. The first hour after surgery the general condition of the patient is worsening with severe polipnea and hypoxia. In the gas analysis is found severe metabolic acidosis $\mathrm{pH} 7.12$, pCO2 16.5 serum bicarbonate 13.5 BE -10. K- 8.2 meq. Because of the mentioned conditions the patient was intubated and placed on respiratory machine with assist controlled. The patient was hemodynamically unstable, and thus she was invasively monitored, requiring inotropic support with norepinephrine and infusion of crystalloid solutions in large amounts up to 8 liters in the first day because of the continuously low central venous pressure. After the cannulation of the left subclavian vein, is inserted a central catheter 2 lumen $12 \mathrm{Fr}$ Arrow and Continuous veno-venous hemodiafiltration (CVVHDF) with Hospal AN69 Multiflow-150 hemofilter ,Gambro was started with the sequent parameters: $180 \mathrm{~mL} / \mathrm{min}$ blood flow, predilution flow of $1000 \mathrm{~mL}$, postdilution of $1000 \mathrm{~mL}$, removal of $100 \mathrm{~mL} /$ hour, prefilter pressure of $180 \mathrm{mmHg}$ and effluent pressure of $70 \mathrm{mmHg}$, with prefilter/effluent relationship $30 / 70$. It is also started an aggressive correction of the metabolic acidosis and hyperkalemia with Ca glukonat and glucose sol + insuline. 15 minutes after starting of the hemofiltration in the next gas analysis is notes severe acidosis with a $\mathrm{K}$ level up to 10 meq.

Due to the fear of a cardiac arrest the parameters of the hemofilter were doubled up to 6 liters per hour fluid exchange. Two hours after the initiation of this therapy the hemodynamic situation improves and the next gas analysis reveals an improved metabolic condition with ph 7,29 pcO2 18.6 serum bicarbonate $18,6 \mathrm{BE}-6$ and $\mathrm{K} 7,5$. We were strict to those regimens for the next hours until the $K$ levels goes down to $5,5 \mathrm{meq}$, the set filter was changed every 12 hours. Six hours after the intervention it is done the fasciotomy of both legs due to the compartment syndrome. In the second day is done the TEE ultrasound and it is found a large thrombus in the left auricle partially in the roof of the atrium, for this reason the treatment with anticoagulants was more aggressive. The patient was kept in hemofiltration for approximately six days and gradually the patient's diuresis started. On the seventh day the patient was extubated and the on the $8^{\text {th }}$ day she was discharged to ward for further treatment of the legs.

\section{Discussion}

The acute renal failure, accompanied by myoglobinuria and hyperkalemia is a serious complication of the rhabdomyolisis due to prolonged ischemia and can be a life threatening condition.

The myoglobin is a protein with a molecular mass up to $17.8 \mathrm{k} \mathrm{Da}$ that can be easily filtrated by the glomeruli and enters the tubular cells via endocitosis where is metabolized. It can be measured in the urine only when the values are above the renal threshold of $1,5 \mathrm{mg} / \mathrm{dl}$, and appears the tea discoloration of the urine when the level of the myoglobine is up to 100 $\mathrm{mg}$ per deciliter. Although the exact mechanism of the glomerular damage through the rhabdomyolisis is still unknown, there are some supposed mechanisms [3] intrarenal vasoconstriction, [4] direct and ischemic tubular injury, and tubular obstruction. The myoglobine is concentrated along the renal tubules, a process that is emphasized from hypovolemia and renal vasoconstriction. Myoglobin seems to have no marked nephrotoxic effect on the tubules unless the urine is acidic. Myoglobine is heme protein that contains iron ions like ferrous oxide, which is necessary to maintain the oxygen molecule. However, molecular oxygen can promote the oxidation of ferrous to ferric oxide, thus generating a hydroxyl radical. This oxidative potential is neutralized from intracellular antioxidant molecules. However, cellular release of myoglobin leads to uncontrolled leakage of reactive oxygen species, and free radicals cause cellular injury [5].

The patients with rhabdomyolisis and renal failure, usually presents with volume depletion from the water sequestration in the damaged muscles. It is of main importance the aggressive correction of the fluid loss that can go up to 10 liters per day depending on the severity of the rhabdomyolisis. Clinical benefits of alkalinization as compared with simple volume repletion are not firmly established [6].

Some authors recommend the use of the renal replacement therapy in rhabdomyolisis only if there is progressive raise in kalium levels, oliguria ( $<0.5 \mathrm{~mL}$ of urine per kilogram per hour for 12 hours), anuria, volume overload, or resistant metabolic acidosis- $\mathrm{pH}<7.1$ [7]. Common techniques of dialysis have shown a limited capacity for removal of circulating myoglobin. In a recent article, some authors have proposed the use of a membrane of super-high-flow continuous hemofiltration with promising results [8]. 
The myoglobine is a molecule with a weight of $17.8 \mathrm{kDa}$, with electric charge and with a spherical shape, it is considered to be large to penetrate the pores through diffusion, so convection is required for it to be eliminated. Siewing coeficient of the myoglobine in the filter membranes CRRT is 0,6 and starts to decrease with the continuing use of the filter [9].

The solution proposed in recent studies by colleagues seems to be feasible and effective in removing myoglobin. The use of a continuous technique with a high-flux membrane hyperpermeable to myoglobin seems to guarantee the elimination of it. One possible limitation is represented by albumin leakage, which should be rigorously tested and evaluated [10].

In our case the patient came outside the time limit for the intervention of thrombectomy, but with the agreement of the patient and the relatives the surgeon decided for the intervention despite the risks due to the hyperkalemia form the rhabdomyolisis. We immediately decided to start the hemofiltration (CVVHDF) with Hospal AN69 Multiflow-100 hemofilter, first with normal volumes and after due to the hyper kalemia we tripled the initial volumes. The mean sieving coefficient for myoglobin was 0.6 during the first $9 \mathrm{~h}$ of therapy and this decreased to 0.4 during the following $7 \mathrm{~h}$. For this reason the filter was changed every 12 hours to make possible the best performance in removing the myoglobin. Mean clearance of myoglobin was $22 \mathrm{ml} / \mathrm{min}$, decreasing to $14 \mathrm{ml} / \mathrm{min}$ during corresponding periods, while the mean ultrafiltration rates were relatively stable at $2,353+/-140 \mathrm{ml} / \mathrm{h}$ and $2,274+/-82 \mathrm{ml} / \mathrm{h}$, respectively. In contrast to myoglobin, the sieving coefficeint for urea, creatinine, and phosphorus remained stable at 1.0 during the first $16 \mathrm{~h}$ of $\mathrm{CVVH}$.

In conclusion, despite the literature suggestions for the use of hyperpermeable membranes in CVVHD for the treatment of the acute renal failure from due to rhabdomiolysis, the use of high volume hemofiltration is an alternative in cases of life threatening complications (hyperkalemia).

\section{References}

1. Bagley WH, Yang H, Shah KH. Rhabdomyolysis. Intern Emerg Med. 2007;2(3):210-8.

2. O'Connor FG, Deuster PA. Rhabdomyolysis. In Cecil Medicine, Goldman L, Ausiello D, Eds., chapter 114, Saunders Elsevier: Philadelphia, Pa, USA, 23rd edition, 2007.

3. Remuzzi G, Perico N, DeBroe ME. Acute kidney injury, in Brenner and Rector's the Kidney, B. M. Brenner, Ed., chapter 29, Saunders Elsevier, Philadelphia: $\mathrm{Pa}$, USA, 8th edition, 2007.

4. Naka $T$, Jones $D$, Baldwin I et al. Myoglobin clearance by super high-flux hemofiltration in a case of severe rhabdomyolysis: a case report. Critical Care. 2005;9(2): R90R95.

5. Ronco C. Extracorporeal therapies in acute rhabdomyolysis and myoglobin clearance. Critical Care. 2005;9(2:141-142,
2005.

6. Bellomo R, Ronco C, Kellum JA, Mehta RL, Palevsky P. Acute renal failure - definition, outcome measures, animal models, fluid therapy and information technology needs: the Second International Consensus Conference of the Acute Dialysis Quality Initiative (ADQI) Group. Critical care. 2004; 8(4):R204R212, 2004.

7. Brendolan A, D'Intini V, Ricci Z, Bonello $M$, Ratanarat $R$, Salvatori G, Bordoni V, De Cal M, Andrikos E, Ronco C. Pulse high volume hemofiltration. Int J Artif Organs. 2004;27(5):398403.

8. Holt SG, Moore KP. Pathogenesis and treatment of renal dysfunction in rhabdomyolysis. Intensive Care Med. 2001;27(5):803-11.

9. Moore KP, Holt SG, Patel RP, Svistunenko DA, Zackert W, Goodier D, Reeder BJ, Clozel M, Anand R, Cooper CE, Morrow JD, Wilson MT, Darley-Usmar V, Roberts LJ 2nd. A causative role for redox cycling of myoglobin and its inhibition by alkalinization in the pathogenesis and treatment of rhabdomyolysis-induced renal failure. $\mathrm{J}$ Biol Chem. 1998;273(48):31731-7.

10. Zager RA, Gamelin LM. Pathogenetic mechanisms in experimental hemoglobinuric acute renal failure. Am J Physiol. 1989;256(3 Pt 2):F446-55. 